\title{
Analysis of the load-bearing capacity of timber members exposed to fire
}

\author{
Kamil Kmiecik ${ }^{1, *}$ and Tomasz Domański ${ }^{1}$ \\ ${ }^{1}$ Cracow University of Technology, The Faculty of Civil Engineering, 24 Warszawska St., 31-155 \\ Cracow, Poland
}

\begin{abstract}
Members of building structures are often made of wood. There are many advantages of using timber, such as quick erection time, good environmental influence and high energy efficiency. But the fire safety requirement is one of the most important issues concerning the design of timber structures. Safe use in structures depends on a proper knowledge and modelling of the chemical and physical reactions related to the increase of temperature inside the timber members. This paper presents a summary of results from numerical studies on the heat transfer through timber members exposed to fire from different sides. The finite element software SAFIR was used to make two-dimensional thermal models of the timber elements. Then the FE models were used to analyze the heat flow within the members under standard ISO-fire exposure interacting from different sides. On the basis of the $300{ }^{\circ} \mathrm{C}$ isotherms, residual crosssections were determined. Then, the load-bearing capacity of the elements exposed to fire from different sides was determined. The obtained results showed that the location of construction members against the fire has a significant impact of the temperature distribution in the cross-section and, as a result, on the load-bearing capacity of the timber members.
\end{abstract}

\section{Introduction}

Wood is a building material widely used in contemporary constructions such as: public, residential, industrial, warehouse, and other buildings. There are many advantages of using timber, such as architectural values, good environmental influence, high energy efficiency and cost-efficient design solutions. One of the biggest disadvantage of using this material in constructions is combustibility. When timber is subjected to elevated temperature, it undergoes structural, chemical and physical changes [1-3]. At first, wood heats up and the moisture will begin to evaporate. When the temperature of wood is around $300{ }^{\circ} \mathrm{C}$ the pyrolysis takes place which cause loss in mass and decrease the strength and mechanical properties. The char layer is not able to carry any loads. In the reduced section, the stress increases. At the same time, the inner part of the cross section heats up, which causes the decrease of material properties. The Eurocode 5 [4] assumes a reduction in the cross section by the charring while the charring rate is constant. Therefore the remaining cross section which is still load bearing can be defined.

\footnotetext{
${ }^{*}$ Corresponding author: kamil.kmiecik@pk.edu.pl
} 
In the fire situation, the stability of structures and buildings depends on the fireresistance of load-bearing constructions. Due to wood charring timber constructions lose their bearing capacity. Resistance of the material to mechanical and thermal loads is substantially reduced. It is assumed that wood at a temperature of over $300{ }^{\circ} \mathrm{C}$ does not carry any loads [5]. Therefore, it is important to know the speed of timber charring.

\section{Heat transfer}

To understanding of fire behaviour of timber members, knowledge of heat transfer is essential. Heat transfer can occur by the three processes: radiation, convection and conduction. Thermal actions are given by the net heat flux $h_{\text {net }}$ to the surface of the member. In fire conditions the net heat flux should contain heat transfer by radiation and convection $[6,7]$.

$$
h_{\text {net }}=h_{\text {net }, c}+h_{\text {net }, r}
$$

where $h_{n e t}$ is net heat flux $\left[\mathrm{W} / \mathrm{m}^{2}\right], h_{n e t, c}$ is convective heat flux $\left[\mathrm{W} / \mathrm{m}^{2}\right]$, and $h_{n e t, r}$ is radiative heat flux $\left[\mathrm{W} / \mathrm{m}^{2}\right]$.

Convection is the heat transfer between a solid and a gas. The heat flux depends on the temperature of the gas in the vicinity of the fire exposed member and on the surface temperature of the member. The equation of the net convective heat flux should be defined as follows:

$$
h_{n e t, c}=\alpha_{c} \cdot\left(\Theta_{g}-\Theta_{m}\right)
$$

where $\alpha_{c}$ is coefficient of heat transfer by convection $\left[\mathrm{W} /\left(\mathrm{m}^{2} \mathrm{~K}\right)\right], \Theta_{g}$ is gas temperature in the vicinity of the fire exposed member $\left[{ }^{\circ} \mathrm{C}\right]$, and $\Theta_{m}$ is surface temperature of the member $\left[{ }^{\circ} \mathrm{C}\right]$.

Radiation depends on the temperature of the radiation source and the material properties of the surface. The equation of the net radiative heat flux should be defined as follows:

$$
h_{n e t, r}=\Phi \cdot \varepsilon_{m} \cdot \varepsilon_{f} \cdot \sigma \cdot\left[\left(\Theta_{r}+273\right)^{4}-\left(\Theta_{m}+273\right)^{4}\right]
$$

where, $\Phi$ is configuration factor, $\varepsilon_{m}$ is surface emissivity of the member, $\varepsilon_{f}$ is emissivity of fire, $\sigma$ is Stephan Boltzmann constant, $\Theta_{r}$ is effective radiation temperature of environment $\left[{ }^{\circ} \mathrm{C}\right]$, and $\Theta_{m}$ is surface temperature of the member $\left[{ }^{\circ} \mathrm{C}\right]$.

The two-dimensional heat transfer element with linear interpolation has been used to model the transient heat conduction within the timber members. The governing partial differential equation is given as:

$$
\frac{\partial}{\partial x}\left(\lambda_{x} \frac{\partial T}{\partial x}\right)+\frac{\partial}{\partial y}\left(\lambda_{y} \frac{\partial T}{\partial y}\right)+\mathcal{Q}=\rho c \frac{\partial T}{\partial t}
$$

where $T(\mathrm{~K})$ is temperature, $\lambda_{x, y}(\mathrm{~W} / \mathrm{mK})$ are thermal conductivities in $x, y$ directions, $\dot{Q}$ $\left(\mathrm{W} / \mathrm{m}^{3}\right)$ is internally generated heat, $\rho\left(\mathrm{kg} / \mathrm{m}^{3}\right)$ is density, $c(\mathrm{~J} / \mathrm{kgK})$ is specific heat, and $t(\mathrm{~s})$ is time. 


\section{Charring of the cross-section}

Timber is a combustible material. When wood is exposed to fire, the pyrolysis occurs. It is a process of thermal degradation that causes physical and chemical changes. This occurs at temperature of $300{ }^{\circ} \mathrm{C}$. The cross-section and the strength and stiffness of the wood close to the heated surface are reduced [8-10]. Determination of fire resistance of structural timber is based on the residual cross-section of uncharred wood. EN 1995-1-2 [4] provides the reduced cross-section method for determining the load bearing capacity of timber elements exposed to fire. In this approach, the cross-section dimensions are reduced due to charring of the timber during a fire. EN 1995-1-2 [4] describes two charring rates: the onedimensional charring rate and the notional charring rate. The notional charring rate is given as a rectangular cross-section. It has the same section modulus as the cross-section with rounded corners. Fig. 1 shows the charring depth for one-dimensional charring and notional charring depth.

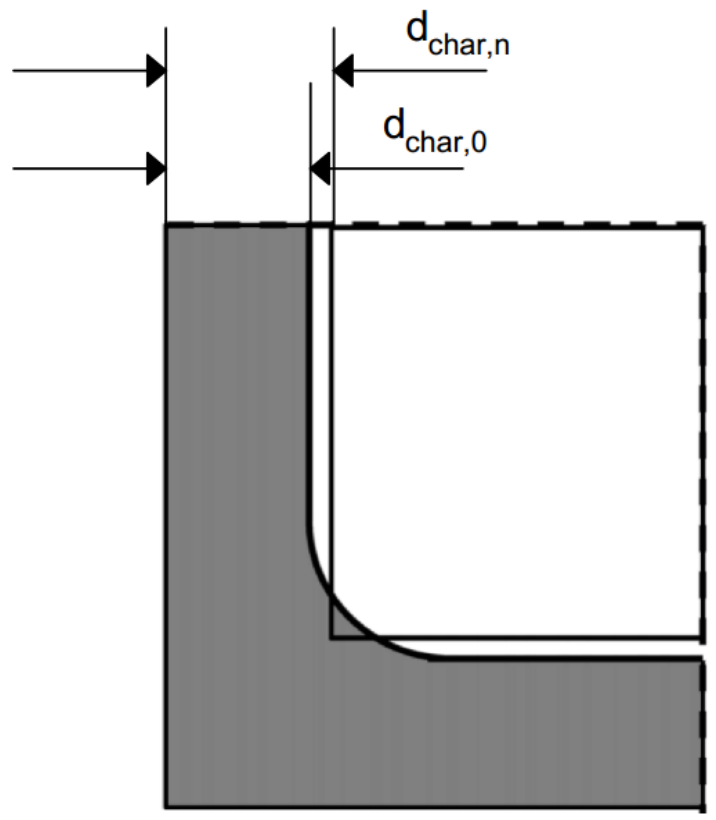

Fig. 1. Charring depth $d_{c h a r, 0}$ for one-dimensional charring and notional charring depth $d_{c h a r, n}$ based on [4].

\section{Finite Element Simulations}

\subsection{Assumptions}

The main purpose of modelling the timber elements using finite element method was to determine the impact of the fire location on heat transfer in cross-sections of timber members. Timber elements are subject of the research. Figure 1 shows the geometry of the elements and fire locations. All elements have dimensions $80 \times 200 \mathrm{~mm}$. The elements were made of wood $\mathrm{C} 20$ and had a moisture content of about $13 \%$. The samples were exposed to standard ISO fire [11] from one (Fig. 2a), three (Fig. 2b) and four (Fig. 2c) sides. 


\subsection{A description of the model}

The finite element software SAFIR [12] was used to analyze heat flow within timber members exposed to fire. The interaction between structural field and temperature field should be taken into account. The software uses the indirect order coupling method. First of all, the temperature field is obtained by thermal analysis of components. Subsequently, the temperature field is applied to the structural field as a body load. The thermal analysis use models of members with mesh dimensions $2 \times 2 \mathrm{~mm}$. The 4-node quadrilateral elements with one temperature degree of freedom were used to mesh the model.

a)
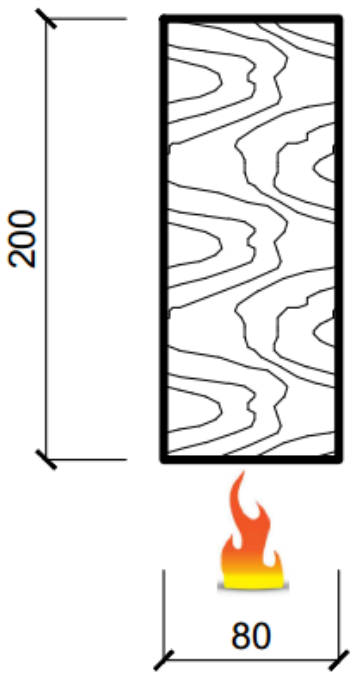

b)
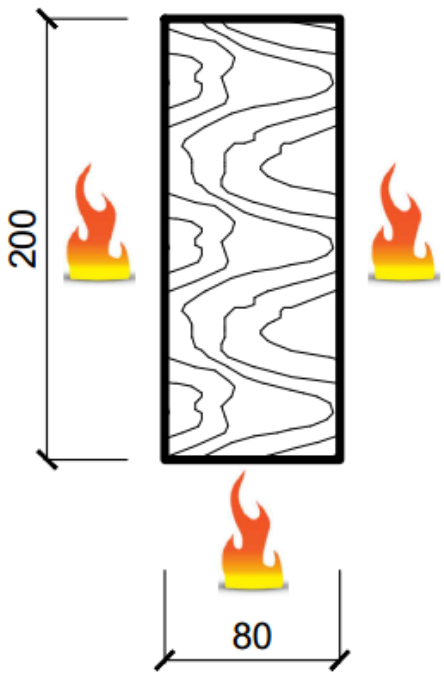

c)

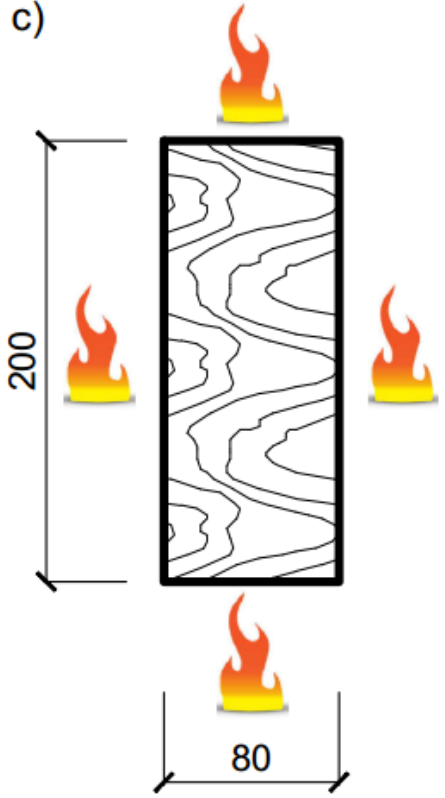

Fig. 2. Timber members exposed to fire from a) one side, b) three sides, c) four sides.

\subsection{Results of FE simulations}

The results of numerical simulations are shown on Fig.3. Figure 3a shows the temperature distribution of the timber member after 15, 30 and 60 minutes of fire exposure from one side. In this case, the isotherms turn linearly. The char layer is formed on the bottom surface of the member. During the fire, the char layer goes deeper into the element. Even after $60 \mathrm{~min}$ of fire exposure, the larger part of the cross-section has the ambient temperature.

Figures $3 b$ and $3 c$ show the temperature distribution of the timber members after 15,30 and 60 minutes of fire exposure from three and four sides respectively. The corners of the members are affected by thermal loads from two surfaces. The isothermal distributions of cross-section change into U-shape. Charring of corners and access of fire on several surfaces causes a quick reduction of the cross-section.

\subsection{The literature review}


Recently, the issue of pyrolysis has been studied by several authors. Researchers compared the results of heat transfer through timber elements exposed to fire with experimental ones from the literature [6]. They used Abaqus software. They concluded that create own material models for thermal analysis of timber subjected to fire, which allows including as many chemical and physical processes as possible. It is a key to develop predictive models for the structural behaviour of timber structures exposed to fire.

Other researchers have carried out fire tests of two timber beams exposed to three-side fire [8]. Then, they compared the results of the experiment with numerical simulations. They concluded that an increase in the density of wood leads to a rise in the fire endurance of a given beam. From experimental tests and FEM results they noticed, that as the load level increases, the fire endurance of the wood beam decreases and the reduction ratio turns smaller.

Authors of paper [7] investigated the charring rate of timber beams exposed to threeside fire. The beams were subjected to the IS0 834 standard fire curve. They found that the timber beam's charring rate reduces as the duration of fire exposure increases and the vertical charring rate is slightly higher than the horizontal one.

\section{Load-bearing capacity of timber members}

\subsection{Residual cross-section}

In designing timber structures, the determination of fire resistance is based upon the residual cross-section of uncharred wood. According to EN 1995-1-2 [4] the char layer is formed at temperature of around $300{ }^{\circ} \mathrm{C}$. It is assumed that the remaining cross-section is able to carry loads. Figure 4 shows the residual cross-sections of timber members exposed to fire.

This is important where the timber member is located in the structure. Column in the light wall will be exposed to fire by one side. This element will have high fire resistance. On the other hand, the timber girder will be exposed to fire from three sides. Therefore, the fire resistance of this element will be low.

\subsection{Load-bearing capacity}

According to EN 1995-1-2 [4] advanced calculation methods for determination of the mechanical resistance shall provide a realistic analysis of structures exposed to fire. They shall be based on fundamental physical behaviour in such a way as to lead to a reliable approximation of the expected behaviour of the relevant structural component under fire conditions. Advanced calculation models should be applied for: the determination of the charring depth, the development and distribution of the temperature within structural members and the evaluation of structural behaviour of the structure or of any part of it.

Using advanced numerical models, the development of charring depth was determined. On the basis of the isotherms $300{ }^{\circ} \mathrm{C}$, the cross-sections that carrying the loads were specified. Then, the load-bearing capacity for compression parallel to the grain was estimated. The results are shown in the Fig. 5. 
$15 \mathrm{~min}$

a)

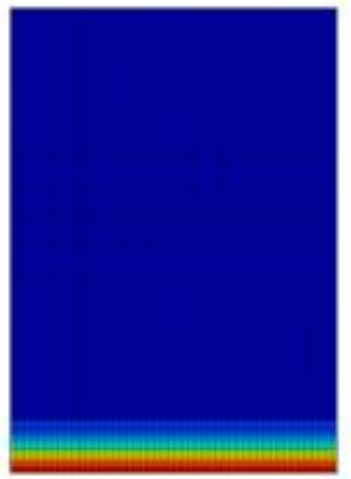

b)

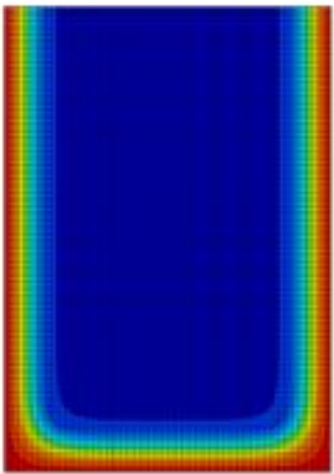

c)

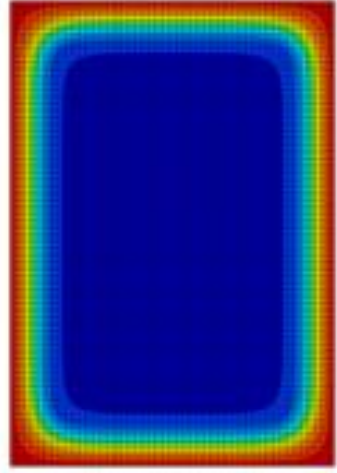

$30 \mathrm{~min}$
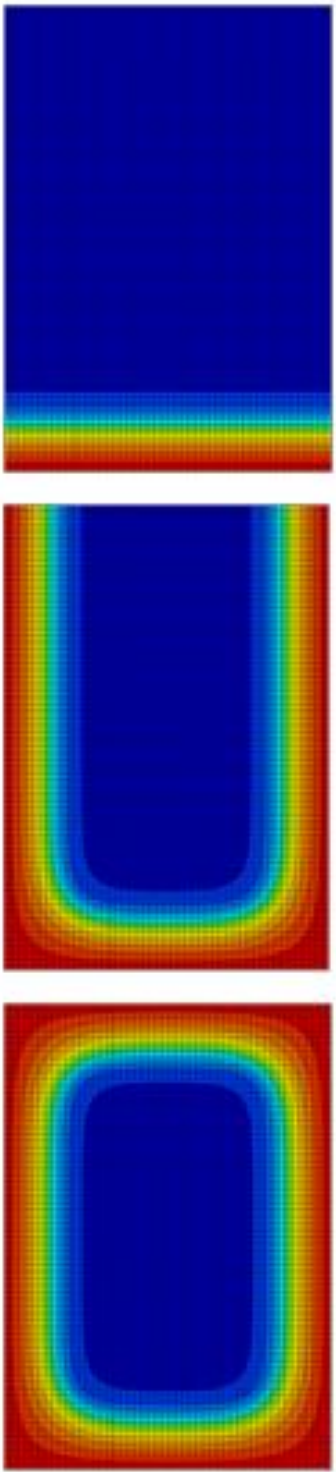

$60 \mathrm{~min}$
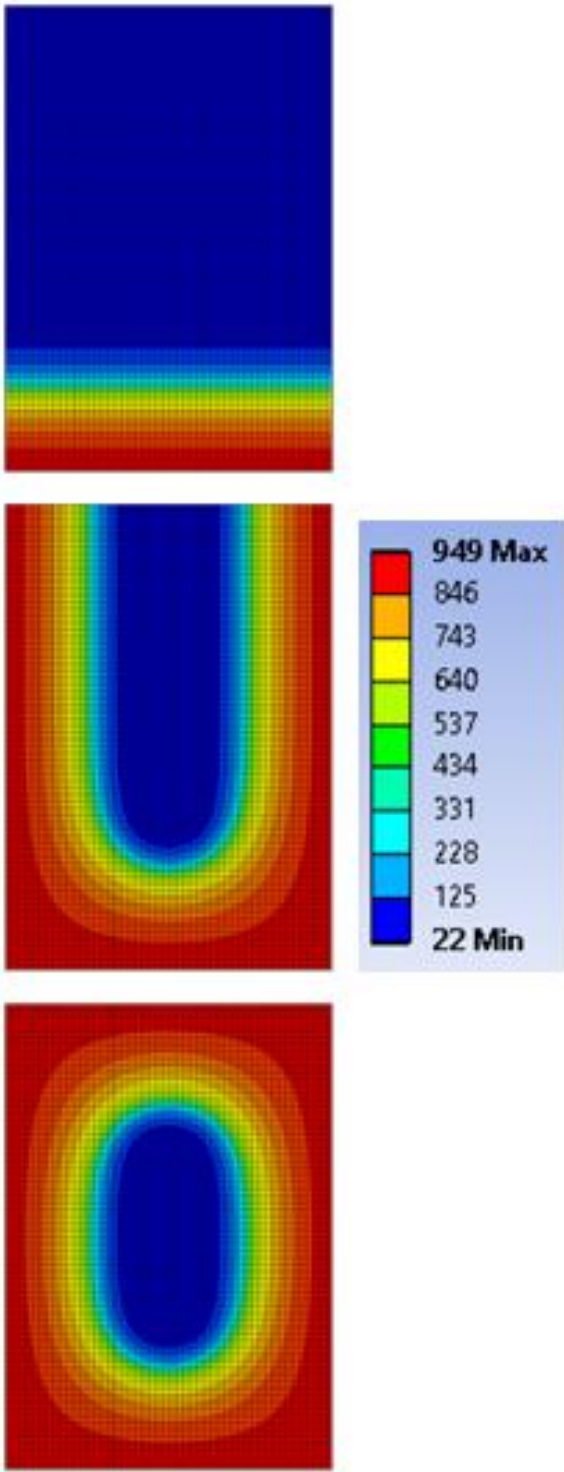

Fig. 3. Temperature distribution of the timber members exposed to standard ISO-fire from a) one side, b) three sides, c) four sides. 


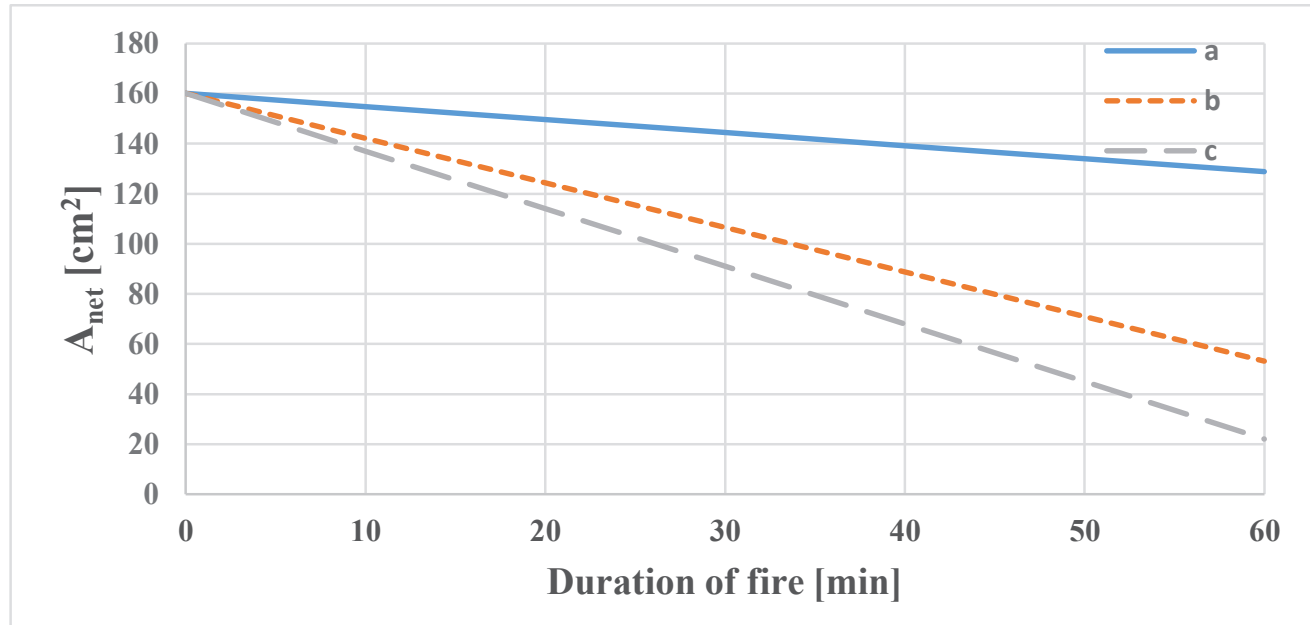

Fig. 4. Residual cross-sections of timber members exposed to fire.

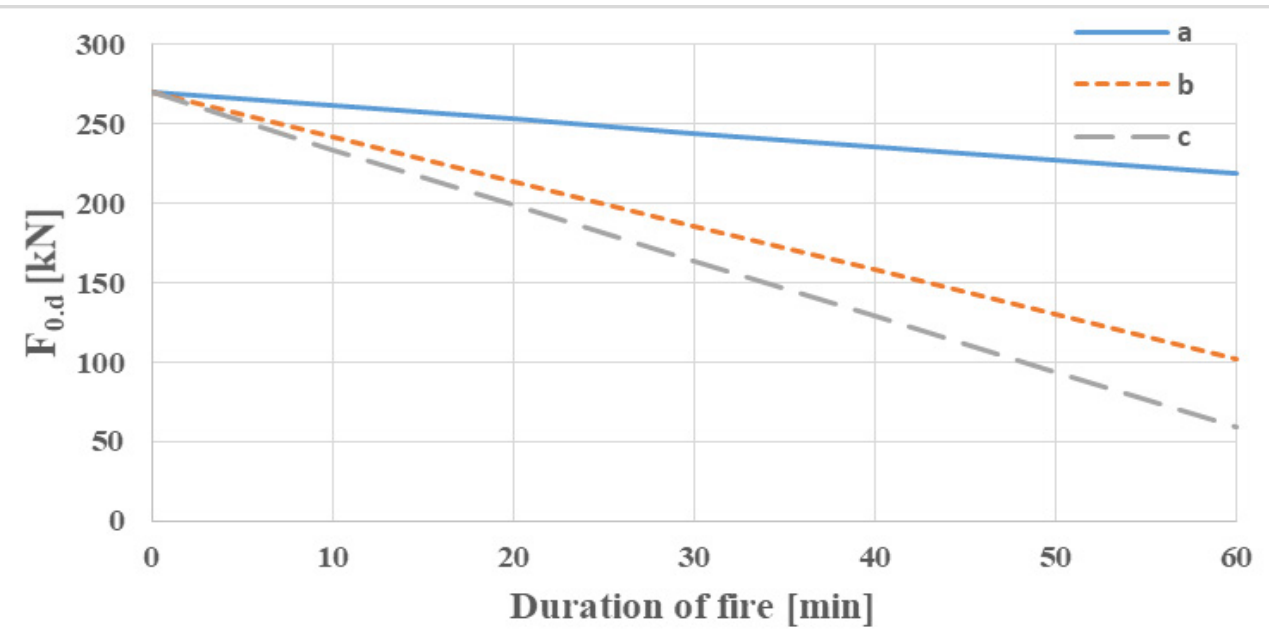

Fig. 5. Load-bearing capacity for compression parallel to the grain of timber members exposed to fire.

\section{Conclusions}

In this paper, a thermal analysis of the timber members exposed to fire were carried to determine the fire resistance. The FE model can provide good predictions of the temperatures through the wood cross-sections. Finite element modelling of the heat flow through the member is a key to determine the fire resistance of a structure element. Therefore, knowledge of the fire behaviour of timber elements is important for safe and effective design. The location of construction members against the fire has a significant impact of the temperature distribution in the cross-section and, as a result, on the loadbearing capacity of the timber members.

When comparing the obtained results with the results of other researchers, good compatibility can be observed. The charring rate is similar to the results of fire tests from the literature. The vertical charring rate is slightly higher than the horizontal one. 


\section{References}

1. V. Babrauskas, Fire Safety J. 40(6), 528 (2005)

2. J. König, Fire Mater. 30(1), 51 (2006)

3. K. Friquin, Fire Mater. 35, 303 (2011)

4. EN 19951 (2004)

5. J. Schmid, M. Klippel, A. Just, A. Frange, Fire Safety J. 68, 81 (2014)

6. V.D. Thi, M. Khelifa, M. Oudjene, M. El Ganaoui, Y. Rogaume, Eng. Struct. 143, 11 (2017)

7. J. Zhang, Z. Liu, Y. Xu, S. Ma, Q. Xu, Tech. Sci. 55, 3434 (2012)

8. J. Zhang, Q. Xu, Y. Xu, B. Wang, J. Shang, Appl. Phys. Eng. 13, 491 (2012)

9. S. Young, P. Clancy, Fire Mater. 25(3), 83 (2001)

10. D. Lange, L. Boström, J. Schmid, J. Albrektsson, Fire Tech. 51, 1311 (2015)

11. ISO 834 (1999)

12. J. Franssen, T. Gernay, J. Struct. Fire Eng. 8, 300 (2017) 